\title{
The Adaptation of Klebsiella aerogenes to the Inhibitory Action of Triethylene-melamine on Growth and Division
}

\author{
By D. J. W. GRANT \\ Physical Chemistry Laboratory, University of Oxford, and \\ Department of Pharmacy, University of Nottingham
}

(Accepted for publication 28 June 1967)

\begin{abstract}
SUMMARY
The aerobic growth of Klebsiella aerogenes adapted to a chemically defined glucose ammonium sulphate medium was studied in the same medium containing triethylene-melamine (TEM). In liquid medium containing TEM up to $205 \mathrm{mg}$. $/ \mathrm{l}$. growth and division were only slightly retarded. With concentrations of TEM greater than about $255 \mathrm{mg}$. $/$. division was strongly inhibited while growth continued slowly, giving filaments the longest of which later separated from the medium as a white pellicle. Further growth and division occurred in the same culture after a lag. During continued subculture in liquid medium containing a constant concentration of TEM the lag was negligible but growth on return to drug-free liquid or solid medium was impaired. At first filament formation increased to a maximum, the growth rate fluctuated and adaptation was rapidly lost during subculture in drug-free medium. The progressive impairment of division was later opposed by a gradual adaptation which eventually produced bacteria of a more nearly normal size, with a steady growth rate and with resistance to precipitation and to higher concentrations of TEM. TEM was less active in solid medium than in liquid medium. The proportion of filaments and the size of the lenticular areas observed in colonies increased with increasing concentration of TEM but decreased with increasing age and size of the colonies.
\end{abstract}

\section{INTRODUCTION}

Triethylene-melamine (TEM), other biological alkylating agents and ionizing radiations have similar biological effects among which is a tendency to inhibit cell division more than growth (increase in mass). TEM causes bacteria such as Escherichia coli to form filaments (Maxwell \& Nickel, 1954; Loveless, Spoerl \& Weisman, 1954; Katchman, Spoerl \& Smith, 1955; Schweisfurth, I959; Kilgore \& Greenberg, I96I). The present work was done as part of a physico-chemical study of the growth of Klebsiella aerogenes in chemically defined media containing inhibitory drugs. During repeated subculture of bacteria in media containing a drug, increasing resistance to the drug is reflected in various responses which may include elimination of an initially long lag, increase in growth rate, changes in the enzyme balance and changes in the proportions of other constituents of the organisms. These responses have been interpreted on the basis of physico-chemical principles (Dean \& Hinshelwood, 1966). Initial growth of $K$. aerogenes in chemically defined media containing proflavine (Davies, Hinshelwood \& Pryce, 1944), $m$-cresol (Spray \& Lodge, I943) or tert.-butanol (Hinshelwood \& Lodge, 1944) gives rise to abnormally long forms. During repeated 
subculture in medium containing one of these drugs, adaptation is marked by a decrease in the proportion of filaments, which indicates that the rate of division is catching up with the rate of growth. The present work shows that the degree of filament formation is a most effective variable for investigating the adaptation of $K$. aerogenes to TEM and, therefore, particular emphasis was placed on a study of the size of the organisms.

\section{METHODS}

Organism. The organism used was a strain of Klebsiella aerogenes NCTC $4 \mathrm{I} 8$ (Aerobacter aerogenes) which was fully adapted to grow in a glucose ammonium sulphate medium by many daily subcultures and which had, so far as could be known, never previously been exposed to TEM or to any other drug.

Triethylene-melamine (2,4,6-tris-aziridinyl-1,3,5-triazine; TEM) was a gift from Imperial Chemical Industries Ltd.

Media. Liquid standard and limiting media and solid glucose ammonium sulphate media and the methods employed for growing the bacteria were the same as those used by Drabble \& Hinshelwood (196I). Liquid and solid media containing TEM were prepared in the same way as media containing streptomycin described by Drabble \& Hinshelwood (196I). The cultures for all measurements were grown in standard medium or on solid glucose ammonium sulphate medium and the inocula were taken from limiting glucose ammonium sulphate medium unless otherwise stated. Subculture of bacteria into fresh media was made daily. One subculture corresponded to about eight generations.

Bacterial mass. The mass of suspended bacteria/ml. culture $(M)$ was estimated turbidimetrically (Drabble \& Hinshelwood, 196r; Grant, 1967) by a modification of the method of Monod (1942). $M$ is expressed as the equivalent number of standardsized cells per $10^{-6} \mathrm{ml}$. giving the same turbidity. In a suspension for which $M$ was I unit the dry weight of bacteria was $0.48 \mu \mathrm{g} . / \mathrm{ml}$.

Growth measurements in liquid media. The lag and mean generation time $(T)$ of cultures were calculated from the growth curves obtained by plotting $\log M$ against the time after inoculation. Lags less than about $40 \mathrm{~min}$. were considered to be negligible.

Growth measurements on solid media. The growth of bacterial colonies on solid media was expressed quantitatively in the manner of Dean \& Hinshelwood (I955):

$\alpha_{t}=\frac{\text { no. colonies of diam. }>0.4 \mathrm{~mm} \text {. on drug medium } t \mathrm{hr} \text { after inoculation }}{\text { no. of colonies of diam. }>0.4 \mathrm{~mm} \text {. on drug-free medium at the same time }}$

$=$ fraction of the viable bacteria on the drug medium which formed colonies greater than the standard size in time $(t) \mathrm{hr}$,

$\alpha_{\infty}=$ fraction of the viable bacteria on the drug medium which ever formed colonies greater than the standard size.

Plots of $\alpha_{t} / \alpha_{\infty}$ against $t$ on drug medium or on drug-free medium were sigmoid, rising from zero to unity. The value of $t$ when $\alpha_{t} / \alpha_{\infty}=0.5$, is called the 'median delay' $(D), \mathrm{I} / D$ is a convenient measure of the rate of growth of the bacteria on solid media.

Bacterial numbers. The total number of bacteria/ml. of culture $(N)$ was determined 
directly by counting the bacteria in a Helber counting chamber (Thoma ruling) under a Baker interference microscope, after killing and preserving the bacteria by adding one drop of formalin $/ \mathrm{ml}$. suspension. Bacteria in colonies were examined after first cutting out the underlying solid medium, then shaking it with a few $\mathrm{ml}$. of saline ( $\mathrm{NaCl} 8.5 \mathrm{~g} . / 1$.) to suspend all the bacteria of the colony, and finally killing and preserving the bacteria as described above.

Bacterial sizes. The length $(l)$ of individual organisms was estimated by comparison with the known dimensions of the squares of the counting chamber or by using a calibrated eye-piece graticule. Bacteria which had not separated completely were always counted and measured as single organisms. The relative degree of inhibition of growth and division of the bacteria was studied by plotting histograms for the distributions of bacterial numbers among bacterial lengths and of bacterial mass among bacterial lengths. If $n$ is the number and $m$ is the mass of bacteria in a group of average length $l$, then number frequency $=n / \Sigma n$ and mass frequency $=m / \Sigma m$. If $d$ is the average density of cellular material, and $a$ is the average cross-section area of the bacteria, $m=d n a l$ and mass frequency $=n l / \Sigma n l$. This approximation is justified by the approximate constancy of the observed width of bacteria of different lengths and by the fact that $M$ was found to be proportional to $\Sigma n l$ for a given number of squares of the counting chamber within the limits of experimental error. The average length of the bacteria is equal to $\Sigma n l / \Sigma n$ and a measure of the average size of the bacteria is given by $M / N$.

The above distributions were summarized by placing the bacteria into the following three larger groups and expressing the number in each group as a percentage of the total number of bacteria in all the groups: $(a)$ bacteria of length from $\circ$ to $10 \mu$, corresponding to the vast majority of organisms in a normal culture of the original sensitive strain grown in standard liquid glucose ammonium sulphate medium containing no drug; (b) bacteria of length from to to $25 \mu$, corresponding to a tiny minority of organisms in a normal culture described above or to a moderate degree of inhibition of division; (c) bacteria longer than $25 \mu$, which appeared as grotesque snake-like filaments and which were formed only when division was strongly inhibited.

\section{RESULTS}

Triethylene-melamine causing 'double growth' in liquid medium

When sensitive bacteria were inoculated into liquid medium containing TEM, from o to $205 \mathrm{mg}$./1., the shape of the growth curves was normal and the end of the logarithmic phase was marked by a decrease in $\mathrm{pH}$ value as in drug-free medium. With increasing drug concentration within this range the value of $M$ in the stationary phase decreased and in TEM $205 \mathrm{mg}$./1. some of the bacteria were actually precipitated from suspension. With TEM 268-2000 mg./1. the growth curves (Fig. I) were unusual and showed 'double growth'. The initial logarithmic growth ('first phase') ceased while the $\mathrm{pH}$ value of the medium was still at its original value and the subsequent decrease in $M$ (of the bacteria in suspension) was accompanied by the formation of a white pellide which adhered to the culture tube at the surface of the medium and which consisted of long snake-like forms. This precipitation did not occur in the absence of TEM, and its degree was insensitive to the rate of aeration and agitation 
of the culture. After a lag a further logarithmic increase in $M$ occurred ('second phase') which was terminated by a decrease in $\mathrm{pH}$ value and a stationary phase (Fig. I).

Triethylene-melamine in liquid or in solid medium causing inhibition of division

The approximate constancy of $N$ over parts of the first phase indicated that growth in this phase was largely an increase in bacterial mass with little division. In accordance with this most of the bacteria grew steadily and continuously up to the maximum value of $M$ (Fig. 2). Thereafter, $M$ and $N$ decreased and the percentage of the smallest organisms increased as a result of the precipitation, and perhaps some division, of

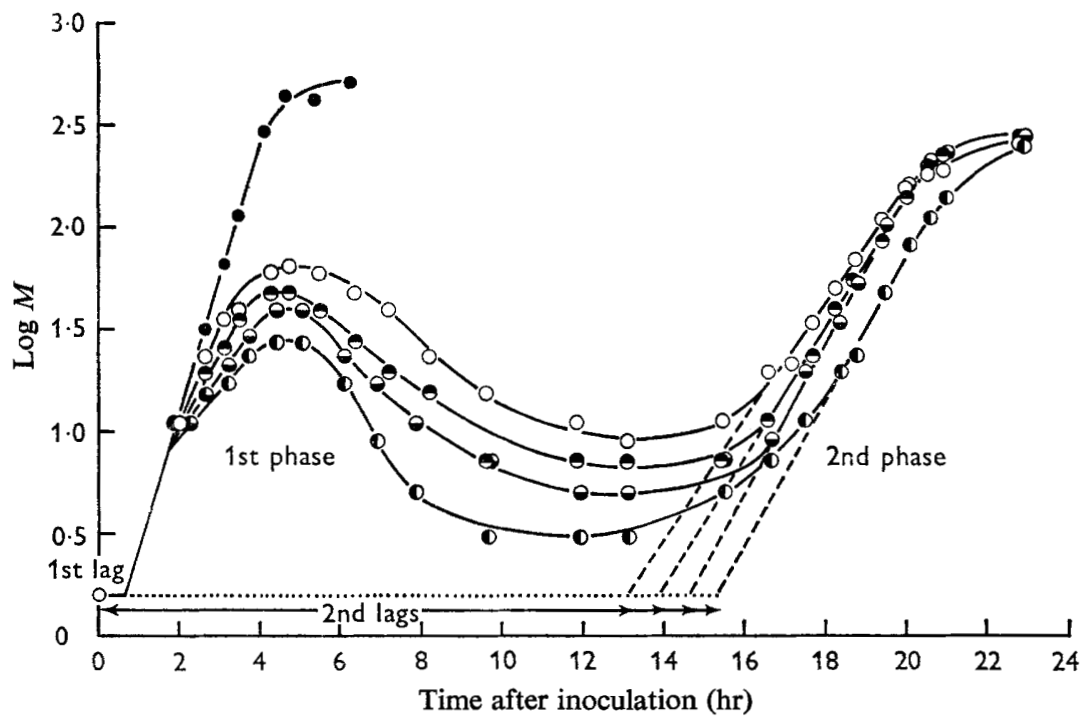

Fig. I. Growth curves of a sensitive strain of Klebsiella aerogenes in glucose ammonium sulphate medium containing the following concentrations of TEM (mg./1.): o (control), ○;268, O; 305, $\ominus ; 353, \ominus ; 399,0$.

longer forms. Throughout the first phase the distribution of the bacteria with length became increasingly wider; this is shown in Fig. 2 by the continuous increase in the average length of the longest $5 \%$ of the bacteria in the culture. This indicated that some of the snake-like forms were still growing in suspension while others were being precipitated.

Throughout the second phase with TEM $353 \mathrm{mg}$./1. the distribution of the number of bacteria with length merely fluctuated between the following limits: $68 \cdot 9-79 \cdot 2 \%$ for bacteria of length $0-10 \mu ;$ I $4 \cdot 7-22 \cdot 7 \%$ for bacteria of length I0-25 $\mu ; 4 \cdot 4-10 \cdot 0 \%$ for bacteria longer than $25 \mu$. Thus, while in the first phase growth occurred largely without division, in the second phase growth and division were more nearly balanced.

The average length of bacteria from colonies grown on solid media, with or without TEM, was much less than that of bacteria from the corresponding liquid media. As division becomes increasingly inhibited relative to growth the longer length groups must become increasingly occupied, whereas the population of the shorter, normal, length groups must decrease. Indeed, this occurred for colonies of the same age $(24 \mathrm{hr})$ and size $(0.4 \mathrm{~mm}$.) with increasing concentration of TEM, and for a given 
TEM concentration ( $8000 \mathrm{mg} . / 1$.) with decreasing age and size of the colonies. Histograms of the distribution of the number and mass of bacteria with length, for samples taken during the first phase in liquid media containing TEM or taken from colonies growing on solid media containing TEM, had only one mode, like those

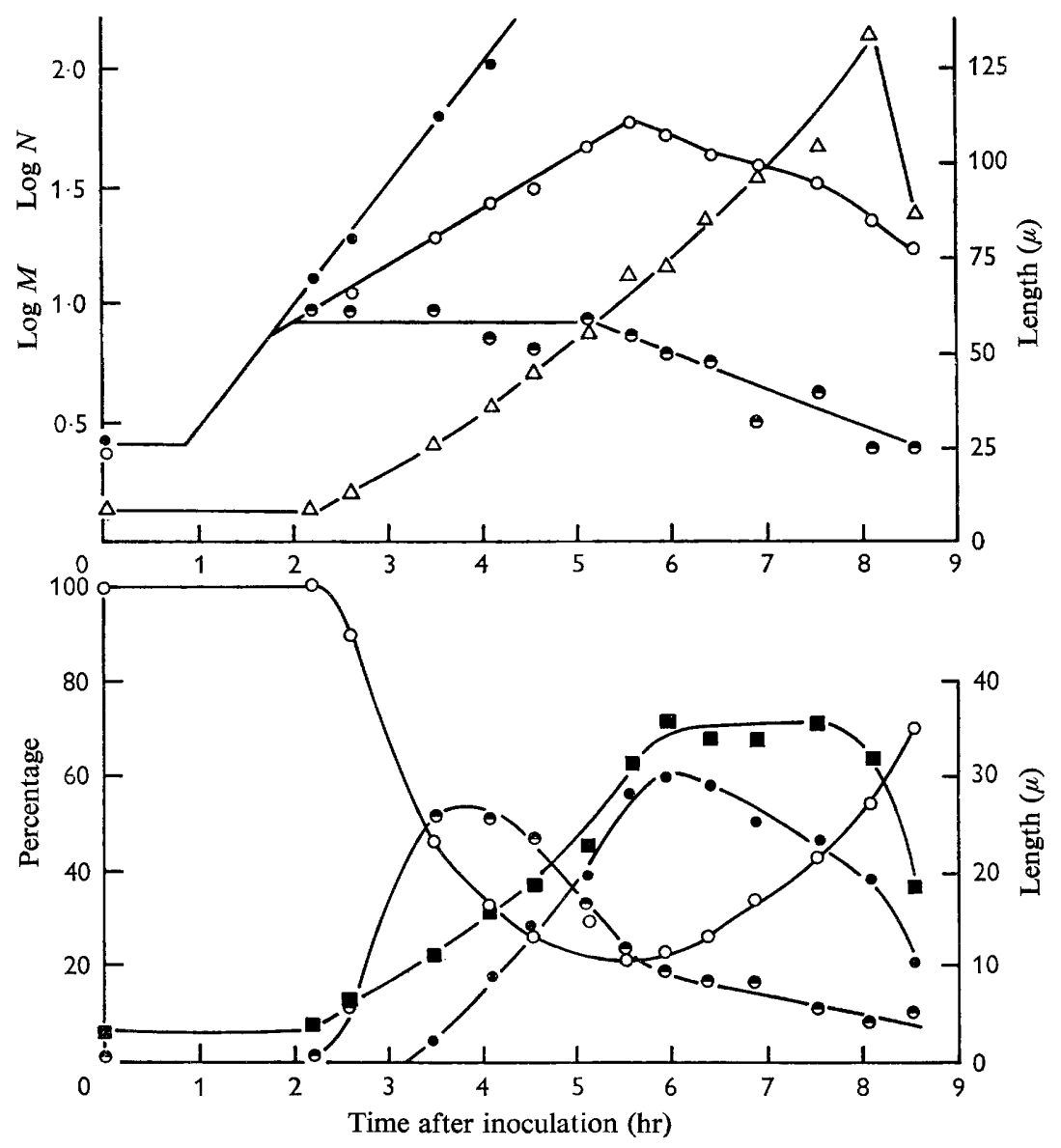

Fig. 2. First phase (initial growth followed by precipitation) for a sensitive strain of Klebsiella aerogenes in glucose ammonium sulphate medium containing TEM $353 \mathrm{mg} . / 1$. Upper: $\log M(\bullet)$ in drug-free medium (control): $\log M(0), \log N(\Theta)$ and the average length of the longest $5 \%$ of the bacteria $(\triangle)$ in drug medium. Lower: $\Sigma n l / \Sigma n=$ average length of all the bacteria ( $\boldsymbol{\omega})$ in TEM medium: the percentage of the total number of bacteria in each of the following groups of lengths in drug medium; o to IO $\mu(0)$, Io to $25 \mu(\Theta)$, longer than $25 \mu(\bullet)$.

for corresponding drug-free cultures. In drug-containing media some of the abnormally long forms consisted of two or more opaque sections connected by translucent membranes as if division were about to occur, and rare, Y-shaped forms with an extra limb joined to the main body were occasionally seen.

\section{Effects of triethylene-melamine on lag, growth rate and colony form}

When sensitive bacteria were inoculated into liquid media containing TEM from 0 to $2000 \mathrm{mg}$./1. the lag was negligible, growth was initially uninhibited (Fig. I) and 
most of the bacteria divided. When $M$ had reached about 8-Io units and $N$ had increased by a factor of about I.8, division almost stopped (Fig. 2) and growth slowed to an approximately logarithmic rate whose mean generation time $\left(T_{c}\right)$ increased with the drug concentration ( $c$ mg./l.) according to a definite relationship (Fig. 3) which may be expressed in either of the following ways:

(a) A plot of $\log \left(T_{c}-T_{o}\right)$ against $c$, where $T_{o}$ is the value of $T_{c}$ in the absence of TEM, shows that $\log \left(T_{c}-T_{o}\right)=0.0053(c-58)$ or $T_{c}-T_{o}=0.49 \exp (0.012 \mathrm{I} c$ ).

(b) A plot of $T_{o} / T_{c}$ against $c$, where the symbols have the same meaning as above, leads to a more easily explicable relationship similar to one discussed by Poole $\&$ Hinshelwood (1940) and by Dean \& Hinshelwood (1966). Since $T_{c}=\ln 2 / k_{c}$, and $T_{o}=\ln 2 / k_{o}$, where $k_{c}$ and $k_{o}$ are the specific growth rates in the presence and absence of TEM respectively, then $T_{o} / T_{c}=k_{c} / k_{o}$. When $c$ was about TEM 200$500 \mathrm{mg} . / 1 ., k_{c} / k_{o}=\mathrm{I}-(c-\mathrm{I} 52) / 4 \mathrm{I} 5$. As $c$ increased from $0, k_{c} / k_{o}$ did not start to decrease until $c$ exceeded about TEM $50 \mathrm{mg}$./l., which shows that the organism tolerated low concentrations of TEM. Furthermore, extrapolation of the linear relationship to $k_{c} / k_{o}=$ I gave a positive value of c, namely, TEM $152 \mathrm{mg} . / 1$. With concentrations of TEM exceeding $500 \mathrm{mg}$. $/ 1 . T$ could not be accurately measured but with TEM up to $2000 \mathrm{mg}$./1. the first phase phenomena were observed, indicating that the initial growth rate was still finite.

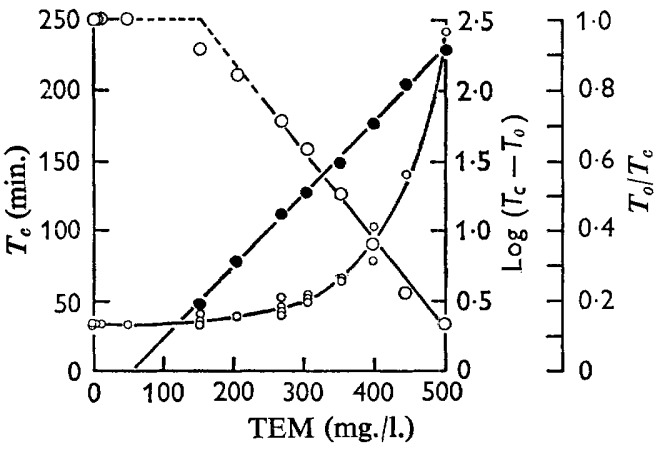

Fig. 3

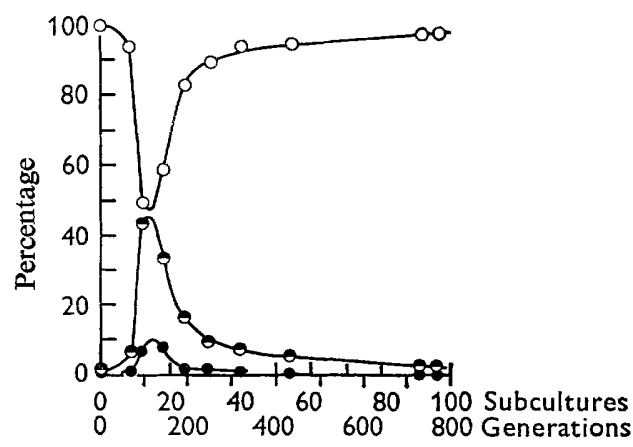

Fig. 4

Fig. 3. $T_{c}(0), \log \left(T_{c}-T_{0}\right)(0)$ and $\mathrm{T}_{o} / \mathrm{T}_{c}(0)$ for growth of a sensitive strain of Klebsiella aerogenes in glucose ammonium sulphate medium containing TEM $c \mathrm{mg}$. $/ \mathrm{l}$., where $T_{c}$ is the mean generation time in the presence of TEM $c \mathrm{mg}$./l. and where $T_{o}$ is the mean generation time of the drug-free control.

Fig. 4. The percentage of the total number of bacteria in each of three groups of organism lengths (o-10 $\mu, 0$; $10-25 \mu, \odot$; longer than $25 \mu, \odot)$ during serial subculture of Klebsiella aerogenes in glucose ammonium sulphate medium containing TEM $2000 \mathrm{mg} . / 1$.

The time between inoculation and the onset of the second phase of growth (the 'second lag') increased linearly with increasing TEM concentration, being, for example, I3.2 $\mathrm{hr}$ at $268 \mathrm{mg}$./1., I6.5 hr at $500 \mathrm{mg}$./1., $20 . \mathrm{I} \mathrm{hr}$ at $750 \mathrm{mg} . / 1$. and $23.9 \mathrm{hr}$ at $1000 \mathrm{mg} . / 1$. Above TEM I000 mg./1. it increased more steeply, being, for example, $39.3 \mathrm{hr}$ at $1500 \mathrm{mg}$. $/ \mathrm{l}$. and $\mathrm{I} 09 \mathrm{hr}$ at $2000 \mathrm{mg}$. $/ 1$. The values of $T$ during the second phase were not related to the concentration of TEM but were distributed about a mean value of $49 \mathrm{~min}$. in an approximately Gaussian manner, with a standard deviation of $8.2 \mathrm{~min}$. for twenty observations. During the stationary phase $M$ was not related to TEM concentration and more bacteria were precipitated. 
On solid media the growth rate decreased with increasing concentration of TEM, $D$ being: I $2 \mathrm{hr}$ with 0-353 mg./1., $24 \mathrm{hr}$ with I000-2000 mg./1., $36 \mathrm{hr}$ with $4000 \mathrm{mg} . / 1$; $57 \mathrm{hr}$ with $8000 \mathrm{mg}$. $/ 1$.

On solid media containing TEM from o to $4000 \mathrm{mg}$./l. practically all the viable bacteria inoculated survived to form colonies, indicating that sensitive bacteria could better withstand the action of TEM on solid medium than in liquid medium. With TEM $8000 \mathrm{mg}$. $/ \mathrm{l}$. I in $\mathrm{I} \cdot 3 \times 10^{4}$ bacteria survived but with TEM I2,000 and $\mathrm{I} 6,000 \mathrm{mg} . / 1$. less than $\mathrm{I}$ in $2.5 \times 10^{8}$ survived.

In agreement with the observations of Dean \& Hinshelwood (I957a), lens-shaped insertions called 'lenticular areas' appeared in ageing colonies growing on media containing TEM. The effect (discussed by Dean \& Hinshelwood $1957 b$ ), increased with age and increasing drug concentration and became pronounced in colonies grown on TEM 4000 and $8000 \mathrm{mg}$./1. from 4 to 7 days after inoculation.

\section{'Training' by repeated subculture in liquid medium containing TEM}

At various stages during the first subculture in liquid medium containing TEM $353 \mathrm{mg}$./1. further subcultures were made into medium of the same type. Subcultures from the first phase grew after considerable lags (8-ro hr), whereas those from the second phase grew after negligible lags although at similar rates (e.g. $T=4 \mathrm{I}-45 \mathrm{~min}$.). The time interval between inoculation of sensitive bacteria into the first medium and the beginning of growth of the second subculture was about $15 \cdot 9-\mathrm{I} 8 \cdot \mathrm{I} \mathrm{hr}$ and was independent of the moment or phase of growth at which the inoculum was transferred from the first to the second sample of medium. A considerable lag after the first phase was therefore a necessary preliminary to further growth, whereas in subsequent subcultures the lags were always negligible and 'double growth' never re-occurred.

During serial subculture in liquid media containing a constant concentration of TEM (353, 1000, $2000 \mathrm{mg} . / 1$.) $T$ fluctuated at first but eventually decreased to a steady value after prolonged subculture (e.g. Table r). The magnitude of the early fluctuations and the final value of $T$ were larger the higher the TEM concentration used. Subculture in liquid medium containing TEM $2000 \mathrm{mg}$./1. enabled all the bacteria to survive on solid medium containing TEM $8000 \mathrm{mg} . / 1$. as compared with only I organism in 13,000 for the sensitive strain.

Thus serial subculture in liquid medium containing TEM led to adaptation of the bacteria, but at the expense of slower growth in the absence of TEM (Table I). Similarly, after 68 or IOI subcultures in liquid medium containing TEM $2000 \mathrm{mg}$. $/ 1$. the rate of colony development on solid medium was decreased; $D$ had increased by between $5 \%$ and $75 \%$ on TEM plates and by $75 \%$ and $300 \%$ on drug-free plates.

The distribution of the number of bacteria with length changed during subculture in standard glucose ammonium sulphate medium + TEM. When the parent was grown in medium of the same type, the distribution fluctuated markedly throughout the first few subcultures with TEM $353 \mathrm{mg}$./1., showing that growth and division had not reached a steady balance. Throughout the $37^{\text {th }}$ and II 7 th subcultures the proportion of longer forms increased to a maximum early in the logarithmic phase and decreased to a constant minimum at the end of that phase. The proportion of filaments at a given point during the I I 7 th subculture was less than that at the corresponding point in the 37 th subculture. When the parent was grown in limiting glucose ammonium 
sulphate medium + TEM, the proportion of longer forms decreased immediately after inoculation and more gradually, being constant and minimal when $M$ was between 40 and 100 units towards the end of the logarithmic phase. Therefore, in a standard test for the degree of filament formation during serial subculture in TEM-containing medium, the bacteria were grown under these latter conditions and were sampled when $M$ was about 80 units.

Table I. Mean generation time $(T)$ during serial subculture of a strain of Klebsiella aerogenes in a chemically defined medium containing a constant concentration of triethylene-melamine (TEM)

Basal medium: glucose + ammonium sulphate + salts $(\mathrm{pH} 7 \cdot 12)$. Incubation temperature: $40^{\circ}$. Growth: aerobic. Strain: initially adapted to basal medium containing no TEM.

\begin{tabular}{|c|c|c|c|c|c|}
\hline $\begin{array}{c}\text { No. of } \\
\text { previous } \\
\text { subcultures in } \\
\text { TEM } 353 \mathrm{mg} . / 1 . \\
\text { before test }\end{array}$ & $\begin{array}{c}T \text { in } \\
\underset{\text { (min.) }}{353 \mathrm{mg} .} / 1 .\end{array}$ & $\begin{array}{c}T \text { in } \\
\text { absence of } \\
\text { TEM (min.) }\end{array}$ & $\begin{array}{l}\text { previous } \\
\text { subcultures } \\
\text { in TEM } \\
2000 \mathrm{mg} . / 1 . \\
\text { before test }\end{array}$ & $\begin{array}{c}T \text { in } \\
\text { TEM } \\
2000 \mathrm{mg} . / 1 . \\
\text { (min.) }\end{array}$ & $\begin{array}{c}T \text { in } \\
\text { absence of } \\
\text { TEM (min.) }\end{array}$ \\
\hline 0 & $55^{*}$ & 29.5 & 0 & $36^{*}$ & 32 \\
\hline I & 39.5 & - & 3 & - & 33 \\
\hline 13 & $4 \mathrm{I}$ & 39.5 & 7 & 69 & - \\
\hline 20 & $4 I$ & 42 & I I & 108 & 66 \\
\hline 25 & $45 \cdot 5$ & $48 \cdot 5$ & 16 & IOI & - \\
\hline 29 & 52 & $46 \cdot 5$ & 17 & $62 \cdot 5$ & 64 \\
\hline 36 & 49 & $39 / 54 \cdot 5$ & 23 & $54 \cdot 5$ & $54 \cdot 5$ \\
\hline 44 & 46 & $45 \cdot 5$ & 30 & $91 \cdot 5$ & 50 \\
\hline 52 & 42 & 43 & 39 & 59.5 & 60 \\
\hline 60 & 40 & $38 \cdot 5$ & 53 & $142 / 54 \dagger$ & $46 \cdot 5$ \\
\hline 74 & 39 & 38 & 90 & $143 / 52$ & 45 \\
\hline II 2 & 33 & 30 & 95 & $144 / 53.5$ & $44 \cdot 5$ \\
\hline I 16 & $32 \cdot 5$ & 31 & - & - & - \\
\hline
\end{tabular}

* Second phase of first subculture

$\dagger 142 / 54$ indicates that growth with $T=142 \mathrm{~min}$. was followed by growth with $T=54 \mathrm{~min}$. etc.

Plots of the percentage of the total number of bacteria in various length groups against the numbers of subcultures or generations in medium containing TEM 353, 1000 and $2000 \mathrm{mg}$./1. (Fig. 4) were very similar in shape. During the early subcultures the degree of filament formation increased to a maximum and then declined as the number of subcultures in presence of TEM increased. The maximum was greater the higher the concentration of TEM and may have resulted from a competition between $(a)$ increasing action of TEM in inhibiting the division mechanisms and $(b)$ increasing adaptation of the bacteria to resist the action of TEM (see Fig. 7 on p. 57 in Hinshelwood \& Lodge, 1944). After many subcultures the distribution of the bacteria with length became narrower, and it and the average bacterial size, as measured by $M / N$, appeared to approach asymptotically that of the original sensitive strain of Klebsiella aerogenes growing in standard drug-free glucose ammonium sulphate medium, showing that growth and division had nearly achieved their original delicate balance. For example, the bacterial number distribution in the standard test during the 105th and 107th subcultures with TEM $353 \mathrm{mg} .11$. (0-10 $\mu, 99.2 \% ; 22-25 \mu$, $0.8 \%$; longer than $25 \mu, 0 \%$ ) was very similar to that for the original sensitive strain in drug-free medium (O-IO $\mu, 99 \cdot 3 \%$; IO-25 $\mu, 0 \cdot 7 \%$; longer than $25 \mu, 0 \%$ ). Similarly, 
bacteria thoroughly adapted to grow with TEM $2000 \mathrm{mg} . / 1$. in liquid medium, when grown on solid medium containing either TEM o or $8000 \mathrm{mg} . / 1$. gave colonies consisting of bacteria with the same distribution among lengths as those of the original sensitive strain growing on drug-free plates; more than $97 \%$ of the bacteria were 0-5 $\mu$ long. For serial subculture in liquid medium containing TEM histograms of the distribution of the bacteria with length had only one mode and, in general, the degree of filament formation was not related to $T$.

At various stages during 'training' to grow in presence of TEM the organism was

Table 2. Reversal of adaptation of Klebsiella aerogenes to triethylene-melamine (TEM) by serial subculture in the absence of TEM

Basal medium: glucose +ammonium sulphate + salts $(\mathrm{pH}=7 \cdot 12)$. Incubation temperature: $40^{\circ}$. Growth: aerobic. Strains: adapted to basal medium containing TEM $1000 \mathrm{mg} . / 1$. $T=$ mean generation time.

Growth in absence of TEM

$\overbrace{\begin{array}{c}\text { No. of } \\ \text { previous } \\ \text { subcultures } \\ \text { before test }\end{array}}^{\begin{array}{c}T \\ \text { (min.) } \\ \text { during } \\ \text { test }\end{array}}$

Test of growth in presence of TEM

$\begin{array}{cccc}\begin{array}{c}\text { Type of } \\ \text { growth } \\ \text { curve }\end{array} & \begin{array}{c}T \\ \text { (min.) } \\ \text { during }\end{array} & \text { Lag } & \begin{array}{c}T \\ \text { (min.) } \\ \text { during }\end{array} \\ \text { Ist phase } & \text { (hr) } & \text { 2nd phase }\end{array}$

Reversion after I subculture in TEM rooo mg./l.

\begin{tabular}{|c|c|c|c|c|c|}
\hline 0 & 32 & a & 77 & . & . \\
\hline 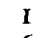 & 33.5 & b & $69 / 90 \cdot 5^{*}$ & . & \\
\hline 6 & 36 & c & $\infty$ & 3 & $58 \cdot 5$ \\
\hline 10 & 32 & d & $82 \cdot 5$ & $I-2 I$ & 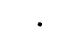 \\
\hline II & 34.5 & d & & $5^{-17}$ & \\
\hline 14 & 35 & d & $62 \cdot 5$ & 13.8 & $5^{2}$ \\
\hline 16 & 37.5 & d & 60 & $7-20$ & \\
\hline 20 & $3 I \cdot 5$ & d & $83 \cdot 5$ & $6-19$ & . \\
\hline
\end{tabular}

Reversion after I8 subcultures in TEM $1000 \mathrm{mg} . / 1$.

$\begin{array}{llllc}44 \cdot 5 & \text { a } & 62 & : & : \\ 46 & \text { b } & 44 / 81 \cdot 5 & : & : \\ 5 \mathrm{I} & \mathrm{a} & 56 \cdot 5 & 5 \cdot 0 & 58 \cdot 5 \\ 38 & \text { d } & 5 \mathrm{I} \cdot 5 & 27 \cdot 5 & : \\ 37 \cdot 5 & \text { d } & 80 & 5-19 & : \\ 38 & \text { d } & 54 \cdot 5 & 9-17 & \end{array}$

Reversion after 29 subcultures in TEM I000 mg./l.

\begin{tabular}{|c|c|c|c|c|c|}
\hline 0 & 42 & $\mathbf{a}$ & 53 & . & \\
\hline I & $4 \mathrm{I} \cdot 5$ & a & $43 \cdot 5$ & . & . \\
\hline 3 & 40 & a & 54 & . & . \\
\hline 9 & $35 \cdot 5$ & b & $33 \cdot 5 / 66$ & . & . \\
\hline 13 & 36 & $\mathbf{a}$ & 55 & . & . \\
\hline $2 x$ & 37 & $\mathbf{a}$ & 45 & . & . \\
\hline 27 & $42 \cdot 5$ & $\mathbf{a}$ & 56 & . & \\
\hline 37 & 30 & $\mathrm{~b}$ & $48 / 90 \cdot 5$ & . & \\
\hline 48 & 29 & b & $50 \cdot 5 / 134$ & & \\
\hline 62 & 30 & c & $\infty$ & $5 \cdot 5-17.5$ & \\
\hline 64 & $37 \cdot 5$ & d & 65.5 & $8-18$ & . \\
\hline 69 & 32 & b & 63 & . & \\
\hline 80 & . & b & $54 / 102 / 190$ & . & \\
\hline 109 & $33 \cdot 5$ & b & $54 / 142$ & . & \\
\hline 140 & $29 \cdot 5 / 52$ & d & $61 / 125$ & $10-20$ & \\
\hline I46 & 42 & c & $\infty$ & $17 \cdot 7$ & $34 \cdot 5$ \\
\hline
\end{tabular}

* 69/90.5 indicates that growth with $T=69 \mathrm{~min}$. was followed by growth with $T=90.5 \mathrm{~min}$. etc. 
repeatedly subcultured in TEM-free medium and the degree of adaptation which the strain then possessed was determined by retesting in TEM medium (Table 2). The pattern observed on retesting was as follows: $(a)$ Initially the absence of any rapid reversal of adaptation was indicated by a negligible lag and a normal logarithmic phase. During the stationary phase some snake-like forms were precipitated from suspension. (b) Later the lag was still negligible but the growth phase was composite: fast growth changed abruptly when $M$ was about 90 units to give what appeared to be slow growth which was wholly or partly a result of the earlier onset of precipitation while growth was still proceeding. Growth and precipitation competed at this early stage of reversion. (c) Sometimes more or less normal growth was preceded by a lag. (d) The final stage of reversion was marked by 'double growth' in two phases on retesting, as for the initial subculture of sensitive bacteria in TEM medium. Precipitation had at this stage overtaken growth and had brought about the decline in $M$ (of suspended organisms). Continued subculture in TEM-free medium gave a strain indistinguishable from the original sensitive strain. Table 2 shows that in the earlier stages of reversion the order of $(a)$ and $(b)$ was sometimes reversed, that in the later stages of reversion $(a),(b)$ and $(c)$ did not always occur in this order and that at all stages of reversion $T$ tended to fluctuate. Reversion is clearly a complex process.

The stability of the impressed resistance increased greatly between the 18 th and 29th subcultures with TEM rooo mg./1., reversion being rapid after one subculture or 18 subcultures, but slow after 29 subcultures (Table 2 ).

As reversion proceeded filamentous forms became progressively rarer in drug-free medium and finally disappeared entirely, leaving bacteria of normal appearance; on retest in TEM medium filamentous forms reappeared and their numbers and average length increased. These changes took place sooner than the changes in the nature of the growth curves on retest in TEM medium; e.g. 44 subcultures in medium containing TEM $353 \mathrm{mg}$./1. gave a strain which, after 94 or I39 subcultures in drug-free medium, afforded bacteria of normal size in the absence of TEM but gave a high proportion of filaments in TEM-containing medium, whereas the growth curves in TEM medium were still almost normal.

\section{DISCUSSION}

The behaviour of Klebsiella aerogenes with triethylene-melamine (TEM) is very unusual (Figs. I, 2, 4). When liquid medium containing TEM was inoculated with the original drug-sensitive strain of Klebsiella aerogenes, there was an initial burst of uninhibited growth and division (Figs. I, 2), which showed that TEM did not act immediately. The effect of a given concentration of TEM on growth and division was less in solid medium than in liquid medium. This is explicable if the reactive ethyleneimine is adsorbed by gel structures in the solid medium or if the bacteria can neutralize the TEM around them more effectively in an immobile medium than in a fluid medium.

During the initial cultivation of sensitive bacteria in liquid medium containing TEM the growth rate in the first phase was not decreased unless the concentration of TEM exceeded about $50 \mathrm{mg}$./1., which implies that the bacteria have a limited capacity to neutralize the drug. The specific growth rate $\left(k_{c}\right)$ during the first growth phase was given by

$$
k_{c} / k_{o}=\mathrm{I}-(c-\mathrm{I} 52) / 4 \mathrm{I} 5 \text {, }
$$


provided that the concentration ( $c \mathrm{mg} . / 1$.) of TEM was between 200 and $500 \mathrm{mg} . / \mathrm{l}$. (Fig. 3). This relationship has certain consequences if the following assumptions are made: (a) there is an equilibrium between the drug in solution and the drug adsorbed by an enzyme in the bacteria; $(b)$ the growth rate of the bacteria is decreased by the inhibition of the enzyme by the drug, such that $k_{c}$ is proportional to the active surface area of the enzyme free from drug. If $S$ is the fraction of the active surface of the enzyme occupied by the drug, then $k_{c} \propto(\mathrm{I}-\mathrm{S})$, therefore

From equations (I) and (2)

$$
k_{c}=k_{o}(\mathrm{I}-S) \text {. }
$$

$$
S=(c-152) / 415 \text {. }
$$

If $c$ lies within the limits stated above and if the above assumptions are correct, equation (3) is the adsorption isotherm of the drug on the surface of the key enzyme.

When the concentration of TEM was between about 500 and $2000 \mathrm{mg}$./1., the growth rate of the first phase still continued to be finite, i.e. $k_{c} \rightarrow 0$, contrary to (I). This may be a manifestation of the short initial burst of growth mentioned earlier, or can be explained by postulating that there was still available for metabolism a residue of sites on the enzyme surface immune to or inaccessible to the drug, i.e. if $S \nrightarrow$ I, $k_{c} \nrightarrow$ o (cf. equation (2)).

The bacteria which grew during the second phase of the first subculture with TEM were selected organisms which had escaped death or precipitation during the first phase. These selected bacteria could be either favoured organisms of different genotypes (first-stage mutants), since TEM is strongly mutagenic to Escherichia coli (Iyer \& Szybalski, 1958; Szybalski, 1960); or statistically favoured or physiologically adapted organisms of the same genotype.

During the growth of the bacteria on solid media or in liquid media, with or without TEM, histograms of the distribution of the number or mass of the bacteria with lengths had only one mode. This seems to indicate that, from the point of view of filament formation, only one strain of organisms was present at a given time, with the possible exception of the first phase of the first subculture with TEM.

The susceptibility of the bacteria to form filaments depends on the state of the culture. After repeated subculture in liquid medium containing TEM, the percentage of filaments was greatest early in the growth cycle and then decreased to constant minimum values towards the end of the logarithmic phase. This can be explained by postulating that commencement of division in fresh medium must await the synthesis of a critical amount of a 'division factor' while growth is already in progress (Spray \& Lodge, I943; Hinshelwood \& Lodge, 1944). A change in the drug medium from limiting to standard glucose ammonium sulphate medium on inoculation caused a decrease in the percentage of filaments early in the growth cycle, which may be attributed to a change in osmotic pressure accompanying the change in medium (Hinshelwood \& Lodge, 1944).

Filaments were formed continuously during serial subculture in drug medium and persisted after many subcultures (Fig. 4), which suggests that all the bacteria were susceptible to inhibition of division and could therefore form filaments. During the early subcultures in drug medium the percentage of filaments at a given point in the growth cycle increased. It seems that a given organism could only form a filament when there occurred at a critical stage in division some special event caused by the 
drug. This event must be a rare one since about roo generations passed before filament formation reached its peak. The susceptibility to filament formation was opposed by a continuing adaptation and the percentage of filaments tended to decrease. The stabilization of adaptation to TEM I000 mg./1. (Table 2) occurred between the I 8 th and 29th subculture which was long after the percentage of filaments had reached its peak (at about the I Ith subculture).

During subculture in liquid medium containing TEM and afterwards during subculture in drug-free medium the growth rate sometimes changed abruptly during growth and often fluctuated from subculture to subculture (Tables I, 2). These irregularities in growth partly reflect the complexities of adaptation and partly arise from the disturbance of the measured growth rate by the precipitation of bacteria from suspension. Any relation which might exist between growth rate and filament formation was thus obscured unless adaptation was so far advanced that the complexities and precipitation had disappeared or unless the true growth rates of individual clones (on solid medium) be considered. For example, after prolonged adaptation of Klebsiella aerogenes to TEM in liquid medium, both the mean generation time $(T)$ (Table I) and the percentage of filaments (Fig. 4) had minimum values, and during initial growth on solid medium containing TEM both the median delay and the percentage of filaments increased with increasing concentration of TEM. The minimum value of $T$ and the maximum percentage of filaments increased with increasing concentration of TEM in serial subculture.

The 'lenticular areas' observed in colonies growing on solid medium containing TEM were probably a result of faults arising in the quasi-crystalline structure of the colonies as the size of the bacteria changed during growth (Dean \& Hinshelwood, $1957 b$ ). In agreement with this, the number and extent of the lenticular areas and the tendency of the size of the bacteria to change during growth increased with age and size of the colonies and with increasing TEM concentration.

Although repeated subculture in liquid medium containing TEM (e.g. $2000 \mathrm{mg} . / 1$.) usually impaired growth in the absence of drug both in liquid medium (Table I) or on solid medium, it brought about the following responses: (I) the growth rate in liquid medium containing TEM was optimal (Table I); (2) nearly all the bacteria survived on solid medium containing TEM $8000 \mathrm{mg}$./1. which allowed the survival of only about $I$ in 13,000 bacteria of the original sensitive strain; (3) the distribution of the bacteria with lengths for growth in liquid medium or on solid medium, with or without TEM, had returned to the distribution for the original sensitive strain growing on the corresponding drug-free medium.

Adaptation of Klebsiella aerogenes to TEM seems to be reflected not so much in an increase of the overall rate of growth as in an increase of the rate of division until it equals the rate of growth and in an increase of the ability of the bacteria to resist precipitation and the lethal effects of TEM.

The author wishes to thank Sir Cyril Hinshelwood, O.M., F.R.S., for guidance, Dr A. C. R. Dean for many practical suggestions, and Dr F. L. Rose and colleagues (Imperial Chemical Industries Ltd) for samples of triethylene-melamine. 


\section{REFERENCES}

Davies, D. S., Hinshelwood, C. N. \& Pryce, J. M. G. (1944). Studies in the mechanism of bacterial adaptation. Trans. Faraday Soc. $\mathbf{4 0 , 3 9 7 .}$

DEAN, A. C. R. \& Hinshelwood, Sir C. (I955). The rate of development of colonies of Bacterium lactis aerogenes on agar plates containing drugs. Proc. R. Soc. B 144, 297.

DeAn, A. C. R. \& Hinshelwood, Sir C. (1957a). The formation of papillae on bacterial colonies I. Proc. R. Soc. B 147, I.

Dean, A. C. R. \& Hinshelwood, Sir C. (I957 b). The formation of papillae on bacterial colonies 11. Proc. R. Soc. B 147, 10.

Dean, A. C. R. \& Hinshelwood, Sir C. (1966). Growth, Function and Regulation in Bacterial Cells. Oxford: Clarendon Press.

Drabble, W. T. \& Hinshelwood, Sir C. (196I). Development of resistance to streptomycin by Bact. lactis aerogenes (Aerobacter aerogenes). I. The role of mutation and of physiological adaptation. Proc. $R$. Soc. B 154, 449.

Grant, D. J. W. (1967). Kinetic aspects of the growth of Aerobacter aerogenes with some benzenoid carbon sources. J. gen. Microbiol. 46, 213.

Hinshelwood, C. N. \& Lodge, R. M. (I944). A physico-chemical study of some induced changes in the morphology of Bacterium lactis aerogenes. A theory of the balance and adaptive variation of certain enzyme processes in bacteria. Proc. $R$. Soc. B 132, 47.

IYer, V. N. \& SzYBALSKI, W. (1958). Two simple methods for the detection of chemical mutagens. Appl. Microbiol. 6, 23.

Katchman, B. J., Spoerl, E. \& Smith, H. E. (1955). Effects of cell division inhibition on phosphorus metabolism of Escherichia coli. Science 121, 97.

Kilgore, W. W. \& Greenberg, J. (I96I). Filament formation and resistance to I-methyl-3-nitro-I nitrosoguanidine and other radiometric compounds in Escherichia coli. J. Bact. 81, 258.

Loveless, L. E., Spoerl, E. \& Weisman, T. H. (I954). A survey of effects of chemicals on division and growth of yeast and Escherichia coli. J. Bact. 68, 637.

Maxwell, R. E. \& Nickel, V. S. (1954). Filament formation in $E$. coli induced by azaserine and other antineoplastic agents. Science 120, 270.

MonOD, J. (1942). Recherches sur la Croissance des Cultures Bactériennes. Paris: Hermann et Cie.

Poole, A. \& Hinshelwood, C. N. (1940). Physico-chemical aspects of bacterial growth. Part vi. The influence of toxic substances on growth rate, stationary population and fermentation reactions of Bact. lactis aerogenes. J. chem. Soc. p. 1565.

SChweISFURTH, R. (1959). Einwirkung einiger Gifte auf Zell- und Nucleoid-teilung bei Bakterien. Zentbl. Bakt. ParasitKde, Abt. II, 113, 48.

SPRAY, G. H. \& Lodge, R. M. (I943). The effects of resorcinol and $m$-cresol on the growth of Bact. lactis aerogenes. Trans. Faraday Soc. 39, 424.

SzYBALSKI, W. (1960). The mechanism of chemical mutagenesis with special reference to triethylene melamine action. Developments in Industrial Microbiology, I, 23I. 